\title{
Awareness of L2 American English Word Stress: Implications for Teaching Speakers of Indo-Aryan Languages
}

\author{
Abdul Malik Abbasi ${ }^{1}$, Masood Akhter Memon ${ }^{2}$, Mansoor Ahmed Channa ${ }^{3}$ \& Stephen John ${ }^{4}$ \\ ${ }^{1}$ Chairperson Department of Allied Subjects, Sindh Madressatul Islam University Karachi, Pakistan \\ 2 English Cadet College Petaro, Hyderabad, Sindh, Pakistan \\ ${ }^{3}$ Department of Basic Sciences, Quaid-e-Awam University, Nawab Shah Sindh, Pakistan \\ ${ }^{4}$ Chairperson Department of Education, Sindh Madressatul Islam University Karachi, Pakistan \\ Correspondence: Abdul Malik Abbasi, Chairperson Department of Allied Subjects, Sindh Madressatul Islam \\ University Karachi, Pakistan. E-mail: amabbasi@smiu.edu.pk
}

\author{
Received: December 3, 2017 Accepted: December 27, $2017 \quad$ Online Published: February 4, 2018 \\ doi:10.5539/ijel.v8n3p101 \\ URL: http://doi.org/10.5539/ijel.v8n3p101
}

\begin{abstract}
This study aims to investigate the word stress placement in English and Sindhi words in learners from Indo-Aryan language and American English backgrounds. Since correct placement of word stress is key for L2 English intelligibility, and it is known that native language background affects English language learners' word stress perception and production. The study explores English language learners' intuition through behavioral data from the native speakers of Sindhi and American native speakers to compare their awareness of word stress in L1 and L2. It further investigates learner's stress patterns by measuring their reports of word stress location in their Sindhi and in their L2 English. There were twenty native speakers (10 from Sindh, Pakistan-10 from Illinois State, America) who were recruited from the location in their countries. Results of three experiments show that Sindhi native speakers have less awareness of stress location in their native language than native English controls, and this effect carries into their L2 English. Teachers of Sindhi-speaking students should be prepared to provide explicit training on word stress.
\end{abstract}

Keywords: Sindhi, English, lexical, stress, perception

\section{Introduction}

In English, word stress is contrastive, meaning that two words may differ by stress location alone i.e., the verb 'record' with the noun 'Record'. Moreover, pronunciation of English word-level stress is highly salient because reduction and co-articulation systematically distinguish stressed from unstressed syllables. In other words, English word stress modifies the meaning of English words, whereas, Sindhi word stress does not change the meaning of Sindhi words, though lexical stress is used for emphasis purpose on the words. The study investigated the intuition of both native speakers i.e., Sindhi and American as to where and how they assign primary stress on word level in their L1 and L2. American native speakers have only been judged for their L1 that is English language whereas, Sindhi native speakers were experimented for L1 and L2.

\section{Literature Review}

\subsection{Word Stress in English}

The placement of word stress is of particular importance for English language learners (ELLs) because research suggests that prosodic features such as word stress affects the intelligibility of L2 English speakers (Munro \& Derwing, 1999), and native listeners 'recall [...] significantly more content and evaluate [...] the speaker significantly more favorably' when primary stress is correctly placed vs. incorrectly placed or missing (Hahn, 2004). Similarly, prosodic accuracy contributes to the overall impression of fluency as measured by intelligibility ratings (Derwing \& Rossiter, 2003). Not only is word stress important for overall intelligibility, it is especially important for comprehending English for Academic Purposes (EAP). Longer words with Latin substrate are much more common in EAP than in everyday English. There are 39 different patterns of syllable stress in words on the widely-used Academic Word List created by Coxhead (2000), according to Murphy and Kandil (2004). Some of these patterns are rare, but mastery of the 14 most common of these patterns is required for 
pronunciation of $90 \%$ of the words. This task is difficult because the placement of stress is not entirely predictable in English, and therefore is difficult to teach and learn (Hammond, 1999).

The difficulty that L2 learners have in accurately producing and perceiving English stress may lie in interference effects from their L1. Prior studies have investigated transfer of word stress in fixed stress languages, or languages which are claimed to have no stress, and found robust evidence that stress patterns of a learners' L1 can interfere with their ability to accurately perceive and produce stress patterns in the target L2 (Peperkamp \& Dupoux, 2002; Archibald, 1997).

Furthermore, evidence suggests that insensitivity to novel stress patterns is not necessarily due to a failure in auditory processing. Speakers of Polish (a fixed stress language) could not reliably report differing stress patterns, yet measurements of their brain activity showed evidence of a neural response to the difference between correctly stressed and incorrectly stressed syllables (Domahs, Knaus, Orzechowska, \& Wiese, 2012). The transfer of stress, or the absence of stress, from the learners' native language has been shown to result in both pronunciation mistakes and decreased intelligibility (Bian, 2013). Despite the importance of stress placement for intelligibility, and the effect of L1 stress on the acquisition of novel L2 stress patterns, the question of L1 interference in L2 stress acquisition remains understudied for languages spoken outside of East Asia and Western Europe.

This paper focuses on L2 English stress acquisition by L1 speakers of Sindhi, an Indo-Aryan language. Indo-Aryan languages are an important case for L2 English stress learning because their word stress patterns are different from English, and because, as official languages of India and Pakistan, there are many adult ESL learners, many of whom learn English for Academic Purposes (EAP).

\subsection{Word Stress in Sindhi}

Specifying the difference between Sindhi and English word stress patterns is difficult because there is a little agreement on the phonology of Sindhi word stress. Initial analyses indicate that Indo-Aryan languages have no stress. However, the data used to draw this conclusion comes from only two languages, Hindi and Urdu, and does not include data from Sindhi (Krishnamurti et al., 1986). Jatoi (1996) analyzes Sindhi and agrees with earlier work that Sindhi has no word stress, while Nihalani (1995), on the other hand, argues that word stress does exist, and it is fixed on the first syllable of a word. Measurements of acoustic factors clarify the matter because the available evidence shows that stressed syllables are not marked acoustically in the same way that English syllables are (Abbasi \& Hussain, 2015).

Data on Sindhi word stress collected by the first author (Abbasi \& Hussain, 2015; Abbasi, 2017; Abbasi, Channa, Kakepoto, Ali, \& Mehmood, 2017) suggest that Sindhi does have word stress, and that rather than being fixed it is weakly quantity sensitive. In a quantity-sensitive language, stress falls on so-called 'heavy' syllables, which contain a long vowel and/or a coda consonant, rather than on 'lighter' syllables with short vowels, and/or no coda consonants. If Sindhi is indeed quantity sensitive, then Sindhi stress is similar to English stress, though the measured acoustic manifestation of stress is much more robust in English. Author tested Sindhi speakers' perceptual judgments of stress location, and reports results from logistic mixed effects regression models showing that syllable weight (light vs. heavy) is a small but significant predictor of stress perception in Sindhi. Abbasi (2017) reports acoustic measurements for stress in disyllables, and shows that the acoustic difference between stressed and unstressed syllables in Sindhi is much less than it is in English. Whether Sindhi has no stress, or has a system of quantity-sensitive stress there is no question that word stress in Sindhi is phonologically distinct from that of English in the location of stress within the word, and is phonetically distinct from English in the acoustic correlates of stress.

Due to the differing typology of stress in English and in Sindhi, we are led to wonder about Sindhi speakers' awareness of word stress in English. The motivation to study stress transfer in Sindhi ELLs is threefold: (1) The phonological status of Sindhi stress is contested, and so native judgments of stress will help to confirm the status of stress in Sindhi (2) Stress transfer has been measured from East Asian languages with no stress and European languages with fixed stress, but not from Indo-Aryan languages such as Sindhi with variably placed stress that differs from English. (3) Word stress is important for English pronunciation, and there are many ELLs with a Sindhi language background. Therefore, information about Sindhi stress transfer has the potential to inform pronunciation pedagogy.

\subsection{Research Questions and Predictions}

In this study, two research questions are asked as follows:

1) Are there differences among Sindhi and English speakers in the awareness of stress in their native 
language?

2) Do Sindhi learners of English show evidence of transfer from their native stress to English?

These questions are used a metalinguistic stress reporting task. During the task, speakers read words, pronounce them to themselves, and mark the location of the stressed syllable. Stress judgments are aggregated across subjects and words and the agreement among subjects in stress marking is calculated for each syllable in the test. Experiments were approved by either the University of Illinois institutional review board (1) or the University of Management and Technology Lahore (2 and 3).

For RQ 1 (experiments 1 and 3) the prediction based on evidence from Author (Abbasi \& Hussain, 2015) that because Sindhi is only weakly quantity-sensitive and phonetic realization of stress is less strong than in English, Sindhi speakers will show low agreement in marking stressed syllables in English words when compared with English speaking controls. For RQ 2 (experiment 2) the study predicts that stress transfer will occur, such that Sindhi speakers will have similar patterns of agreement in L2 English as in L1 Sindhi, even though the two languages differ in the manifestation of stress.

\section{Experiment 1}

This study involved English speakers marking the stressed syllable in English words. English word stress is known to be salient, and so this condition is included as a control to establish that this metalinguistic task is appropriate for measuring speaker intuitions of stress locations.

\subsection{Procedure}

Participants saw the following instructions: 'You will see a word written down, and then the word separated into syllables. Say the word to yourself in your head as many times as you wish. Then mark down which syllable or syllables is stressed. Even if you are not totally sure, make your best guess. You must mark at least one syllable in each word.' Participants were then shown a sample response, with the word 'away' in which the syllable 'way' was stressed. Most subjects finished the task within 15 minutes.

Table 1. An example of syllable in the word below

\begin{tabular}{lll}
\hline Mark the stressed syllable in the word below \\
\hline career
\end{tabular}

The methodology is an adaptation of Rapid Prosody Transcription (RPT) (Mo, Cole, \& Lee, 2008). RPT collects annotations of prosodic features from a group of naïve transcribers, rather than a small number of experts. Transcribers are given minimal instruction and asked to make their best guess as to locations of prosodic features. RPT has the advantage of avoiding researcher bias and providing agreement data which gives researchers a continuous score of prominence (based on how many speakers marked the syllable), rather than a binary judgment from one expert.

\subsection{Stimuli}

Subjects marked stress in 150 words in English. The words varied in length from one to five syllables and were designed to be frequent and familiar to those with an eighth-grade vocabulary (see table 2). There were an equal number of words of each syllable length. Words that may have differing stress locations depending on dialect, such as aluminum (aLUMiNUM vs. aluMINium) were avoided.

Table 2. Example words used in experiment 1

\begin{tabular}{lll}
\hline SN & Number of Syllables & Example words \\
\hline 1 & Two syllables & apple, teacher \\
2 & Three syllables & fantastic, important \\
3 & Four syllables & television, explanation \\
4 & Five syllables & Mediterranean, sophisticated \\
\hline
\end{tabular}

\subsection{Subjects}

Ten native English speakers were recruited on Amazon Mechanical Turk, an online marketplace for human intelligence tasks, including surveys and experiments. A description of our experiment was posted on an internal 
message board, and respondents completed a survey online, and then were compensated \$2.50. Mechanical Turk settings were adjusted to allow only responses coming from IP addresses in the United States, and all participants self-identified as monolingual native speakers of English from the United States with no speech impairment.

\subsection{Data Analysis}

Because word stress is marked acoustically in English, it was predicted that English speakers would have strong intuitions as to stress location, which would be clear even in a metalinguistic judgment task. As such, it was predicted high agreement for Native English speakers in this task. If agreement is high, the study expects that unstressed syllables (which the study identifies based on dictionary entries) would be left unmarked by most subjects, and that stressed syllables would be marked by nearly all subjects.

\section{Results}

The results are shown in fig. 1 as a histogram showing the number of syllables that are marked as stressed by every possible number of listeners, from zero to 10 . That is, the leftmost bar shows a raw count of the number of syllables marked by zero speakers, and the rightmost bar shows a raw count of the number of syllables marked by all 10 speakers. If listeners are in perfect agreement about the location of stress in the words they hear, the study expects to see a bimodal distribution, with one peak near zero for all the unstressed syllables that few people identified as stressed, and another peak near 10 for all the stressed syllables that most people identified as stressed. There should be few syllables in the middle of the distribution. The expected distribution is evident in the results of experiment 1 (see fig. 1). These results confirm that the task is appropriate for measuring stress location and that the expected pattern of stress identification is found in a language with salient word stress.

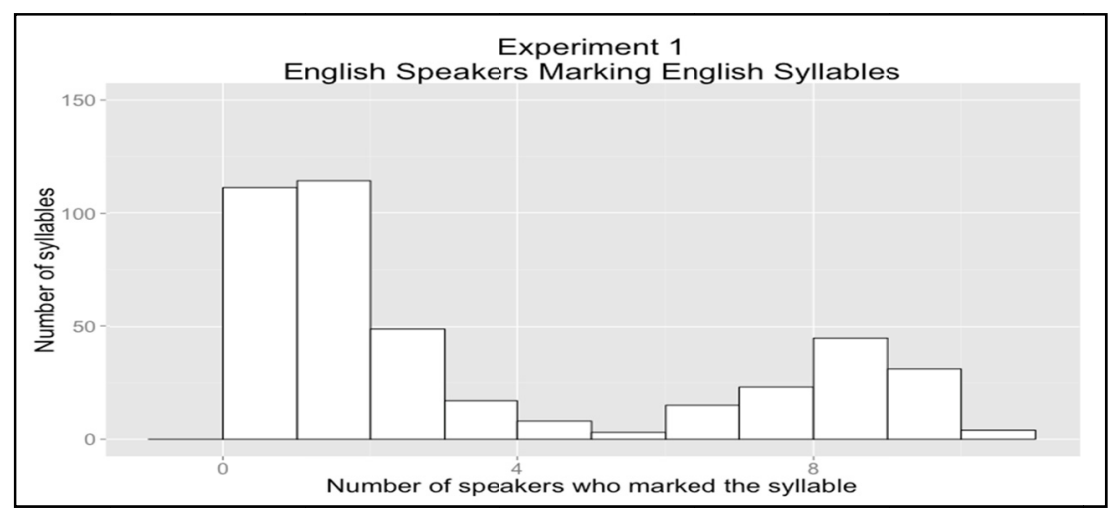

Figure 1. Counts of syllables marked as stressed by English speakers

\section{Experiment 2}

\subsection{Procedure \& Stimuli}

Procedure and the stimuli were the same as in Experiment 1

\subsection{Subjects}

Judgments were obtained from 10 adults recruited from the university community in Karachi and Lahore. All spoke the Utradi (Northern) dialect of Sindhi; they all had at least sixteen years of education in the region where Utradi Sindhi is spoken and had also formal education in Sindhi language. All subjects spoke Sindhi as their native language at home and at their work place. As is common in Pakistan, many of the speakers spoke English and Urdu as well.

\subsection{Data Analysis}

Sindhi speakers had a very different pattern of responses from the English speakers. If the histogram is examined as to how many Sindhi speakers marked stress for each syllable in the Sindhi word list, there is a clear unimodal distribution in which most syllables were marked by 2,3 , or 4 subjects, with relatively few syllables marked as stressed by no subjects and very few syllables marked as stressed by most or all of the subjects.

\section{Results}

A Wilcoxon rank sum test with continuity correction shows evidence that the distribution of scores differs significantly between Sindhi native speakers and English native speakers, when each is marking syllables in their 
own language $(W=120885.5, p<.001)$. This suggests that Sindhi speakers' intuitions about the location of stress in Sindhi are different than English speakers' intuitions about the location of word stress in English. Because the stimuli were the same English words as in experiment 1, the study can directly compare the results of experiment 1 and experiment 2. For each syllable of each word, a total count of the number of English speaking and Sindhi speaking subjects who marked it as stressed was taken. A paired sample t-test comparing these totals for Sindhi speakers and English speakers showed that Sindhi speakers' responses differed significantly from English speakers' responses. $(t=2.1479, d f=419, p=0.03229)$. Overall, it seems clear that Sindhi speakers have different intuitions about the location of word stress in their L2 English than native English speakers do. Sindhi speakers show more disagreement than English speakers, and very few syllables are consistently marked by all Sindhi speakers, in contrast to Native American speakers.

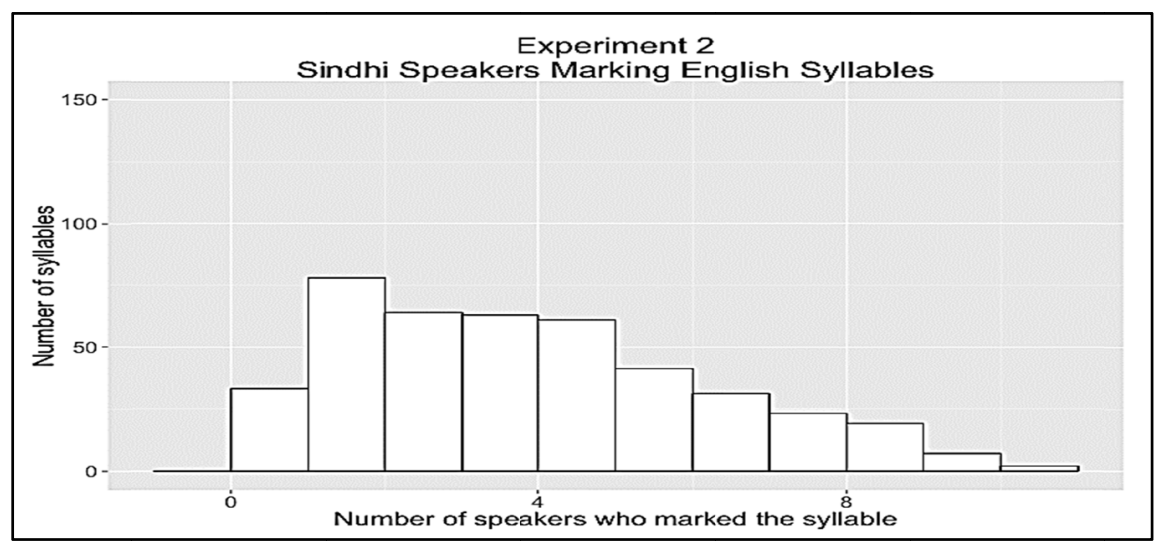

Figure 2. Counts of syllables marked as stressed

\section{Experiment 3}

Experiments 1 and 2 show different patterns of agreement for Sindhi and English speakers, and the study believes they are important first evidence that Sindhi learners of English differ from native speakers in their metalinguistic judgments of stress. To determine whether these effects are due to transfer of word stress from their native language, the study replicated experiments 1 and 2 with Sindhi speakers marking Sindhi words.

\subsection{Procedure}

Experiment two followed a similar procedure to experiments 1 and 2, with small differences due to logistical factors. This experiment was conducted in person. To clarify syllable boundaries, words were written both in Sindhi script and the corresponding Roman transcription, with columns next to the word to indicate the number of syllables. The subjects were asked to mark the column corresponding to the syllable that they judged to be the most prominent (stressed) syllable for each word.

As in experiments 1 and 2, subjects were instructed to make their best guess and to mark the stressed syllable or syllables in the word. However, because word stress is not a familiar concept to many Sindhi speakers, the subjects were given an additional brief definition of stress and the first author gave two example words (not included in the experimental stimuli), identifying in each the syllable judged by the first author as the location of primary stress. Subjects were explicitly told that they should report their own judgments without concern for whether their judgment agreed with that of another speaker, including the first author. As in experiment 1, they were instructed to read each word aloud as many times as necessary to judge which were the most prominent syllable or syllables, and then to mark those syllables as the location of stress by placing a check corresponding to the syllable position in the word.

\subsection{Stimuli}

Subjects marked 150 high frequency Sindhi words. Similar to experiment 1, the words included in the sample were chosen to include all possible types of syllable (heavy vs. light), to include words with 2, 3, 4 and 5 syllables, and to avoid borrowings which might not follow typical Sindhi stress patterns.

\subsection{Subjects}

Ten subjects who did not participate in experiment 2, participated in experiment 3. Their demographic and linguistic profile was matched to subjects in experiment 2 . To increase the small data sample, the first author, an adult native Sindhi speaker, also took part in the study. The study believes this is justified and because the 
purpose of the experiment is explicitly obvious to subjects and the location of Sindhi stress is unknown. In other words, researcher bias was not a concern in this study-the researcher could not know, as to what is the "right" syllable to mark stress on, since it is not reported in the dictionary and different phonological theories predict different locations.

\subsection{Data Analysis}

Results in experiment 3 mirror results of experiment 2. Most syllables were marked as stressed by 2, 3, or 4 speakers, and very few were marked by all ten speakers or marked by no speakers. This suggests that, even in their native language, Sindhi speakers do not have strong awareness of the location of word stress. This is consistent with results of Abbasi (2017), which suggests that stressed syllables in Sindhi are not realized phonetically with the same magnitude of acoustic prominence as stressed syllables in English. It is also consistent with earlier work that suggests that Sindhi has no word stress.

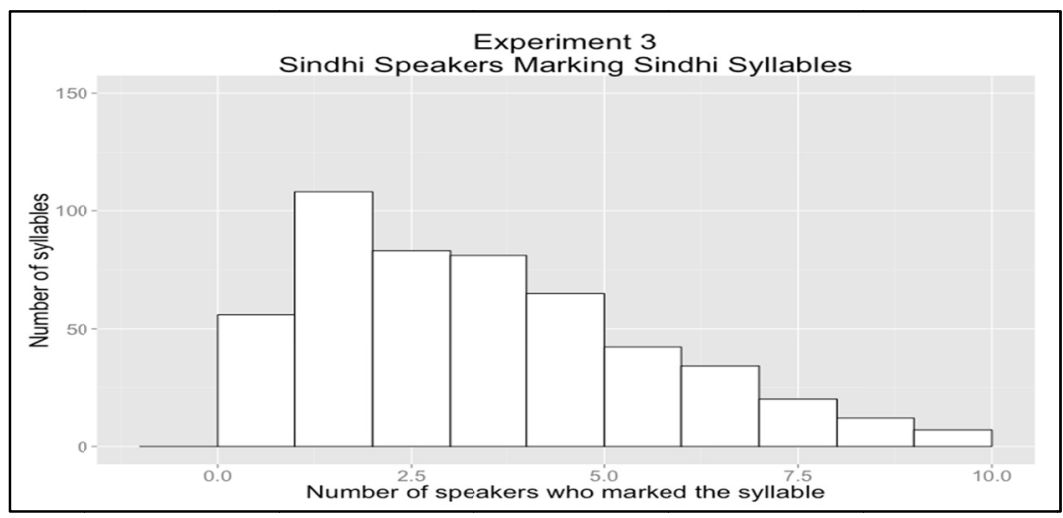

Figure 3. Counts of syllables marked as stressed

\section{Discussion}

This study investigated two things. First, the study asked whether Sindhi speakers show awareness of stress in their L1, comparable to English speakers. The study provides evidence that Sindhi speakers are not aware of word stress in their own language in the same way that native English speakers are, in that they agree very seldom on the location of stress in a word. This suggests that Sindhi speakers are not producing stress properly, do not perceive their own productions as having salient word stress, or both. Results of these studies are consistent with Sindhi speakers transferring the stress patterns in their own language to English. This finding has important implications for teaching English to speakers of Sindhi. A teacher teaching Sindhi ELLs should be careful to describe the concept of word stress, and it may be beneficial to explicitly teach stress placement in L2 English, as the results suggest Sindhi speakers may be completely unfamiliar with the idea of word stress, and unable to hear it even in their native language.

\section{Conclusion}

As it stands, this study sample size is too small to apply the results to the wider population of Sindhi speakers. In addition, this data relies on intuition rather than acoustic samples. In future studies, the study will recruit larger populations and have speakers listen to samples with American English dialects and with Sindhi dialects. The study also plans to use mixed effects regression to both investigate and control for individual variation in stress perception. The results from future studies, combined with the broader project on the theoretical phonology of Sindhi, can provide information which could make critical improvements in pronunciation pedagogy to improve intelligibility of the millions of speakers of Sindhi and other Indo-Aryan languages learn EAP as a second (or third, or fourth...) language. Thus, teachers of Sindhi-speaking students should be prepared to provide explicit training on word stress. Thus, the study reflects a fundamental difference in phonology of word stress in Sindhi and in English-Sindhi word stress is less salient than English word stress, and its location is not obvious even for native speakers. The results show that Sindhi speakers are not able to consistently mark the location of stress in English, despite the fact that it is contrastive, and much more acoustically salient as typically pronounced. This pilot experiment opens up a new and fruitful vein of research: how the phonology of Sindhi word stress affects Sindhi-speaking learners of English.

\section{Acknowledgments}

The author owes a great debt of gratitude to Professor Jennifer Cole, (my doctoral dissertation co-advisor) 
University of Illinois Urbana-Champaign (UIUC) USA for her valuable comments on the paper, while I had a visiting scholar status for my Split PhD program at UIUC. I am grateful to Amelia Kimball, (PhD Candidate) at UIUC for collecting data from American English speakers and helping me complete the task. The comments really enhanced the quality of this paper. The author is also thankful to the American and Sindhi speakers who provided the data examined with accuracy and patience.

\section{References}

Abbasi, A. M. (2017). The stress pattern of Sindhi and English. Munich. Lincom Europa. Germany.

Abbasi, A. M., Channa, M. A., Kakepoto, I., Ali, R., \& Mehmood, M. (2017). A Perceptual Study of Phonological Variations in Pakistani English. Toronto. International Journal of English Linguistics, 8, 91-100. http://doi.org/10.5539/ijel.v8n2p92.

Abbasi, A. M., \& Hussain, S. (2015a). Phonetic analysis of lexical stress in Sindhi. Sindh University Research Journal-SURJ, 47(4), 749-756.

Abbasi, A. M., \& Hussain, S. (2015b). The role of pitch between stress and intonation in Sindhi. Annual Research Journal of English Language Forum, 17, 09-24.

Abbasi, A. M., \& Hussain, S. (2012). Syllable structure and syllabification in Sindhi-English loanwords. International Journal of Researchers, 1(4), 120-134.

Archibald, J. (1997). The acquisition of English stress by speakers of non-accentual languages: lexical storage versus computation of stress. Linguistics, 35(1), 167-181. http://doi.org/10.1515/ling.1997.35.1.167

Bian, F. (2013). The Influence of Chinese Stress on English Pronunciation Teaching and Learning. English Language Teaching, 6(11). http://doi.org/10.5539/elt.v611p199

Coxhead, A. (2000). A New Academic Word List. TESOL Quarterly, 34(2), 213-238. http://doi.org/10.2307/3587951

Derwing, T. M., \& Rossitor, M. J. (2003). The Effects of Pronunciation Instruction on the Accuracy, Fluency, and Complexity of L2 Accented Speech. Applied Language Learning. Retrieved from http://eric.ed.gov/?id=J669790

Domahs, U., Knaus, J., Orzechowska, P., \& Wiese, R. (2012). Stress "deafness" in a language with Fixed Word Stress: An ERP Study on Polish. Frontiers in Psychology, 3. http://doi.org/10.3389/fpsyg.2012.00439

Hahn, L. D. (2004). Primary Stress and Intelligibility: Research to Motivate the Teaching of Suprasegmentals. TESOL Quarterly, 38(2), 201-223. http://doi.org/10.2307/3588378

Hammond, M. (1999). The phonology of English: A prosodic optimality-theoretic approach. Oxford: Oxford University Press, UK.

Jatoi, A. N. (1996). Linguistics and Sindhi language (3rd ed.). Hyderabad, Pakistan: Sindh University Press.

Krishnamurti, B., Masica, C. P., \& Sinha, A. K. (1986). South Asian languages. Motilal Banarsidass.

Mo, Y., Cole, J., \& Lee, E. (2008). Naïve listeners' prominence and boundary perception. Proceedings of Speech Prosody 2008. Campinas, Brazil.

Munro, M. J., \& Derwing, T. M. (1999). Foreign Accent, Comprehensibility, and Intelligibility in the Speech of Second Language Learners. Language Learning, 49(s1), 285-310. http://doi.org/10.1111/0023-8333.49.sl.8

Murphy, J., \& Kandi, M. (2004). Word-level stress patterns in the academic word list. System, 32(1), 61-74. http://doi.org/10.1016/j.system.2003.06.001

Nihalani, P. (1995). Sindhi. Journal of the International Phonetic association, 25(02), 95-98. http://doi.org/10.1017/S0025100200005235

Peperkamp, S., \& Dupoux, E. (2002). A Typological Study of Stress Deafness. In C. Gussenhoven \& N. Warner (Eds.), Laboratory Phonology, 7. Berlin: Laboratory Phonology. http://doi.org/10.1515/978311097105.1.203

\section{Copyrights}

Copyright for this article is retained by the author(s), with first publication rights granted to the journal.

This is an open-access article distributed under the terms and conditions of the Creative Commons Attribution license (http://creativecommons.org/licenses/by/4.0/). 